\title{
Genetic Diversity and Pathogenic Variability Among Isolates of Colletotrichum Species from Strawberry
}

\author{
Béatrice Denoyes-Rothan, Guy Guérin, Christophe Délye, \\ Barbara Smith, Dror Minz, Marcel Maymon, and Stanley Freeman
}

First and second authors: UREFV, INRA, BP 81, 33883, Villenave d'Ornon Cedex, France; third author: Laboratoire de Malherbologie et Agronomie, INRA, BV 1540, 21034, Dijon Cedex, France; fourth author: U.S. Department of Agriculture-Agriculture Research Services, Poplarville, MS 39470; fifth author: Institute of Soil, Water and Environmental Sciences, ARO, The Volcani Center, P.O. Box 6, Bet Dagan 50250; and sixth and seventh authors: Department of Plant Pathology, ARO, The Volcani Center, P.O. Box 6, Bet Dagan 50250, Israel.

Accepted for publication 25 September 2002.

\begin{abstract}
Denoyes-Rothan, B., Guérin, G., Délye, C., Smith, B., Minz, D., Maymon, M., and Freeman, S. 2003. Genetic diversity and pathogenic variability among isolates of Colletotrichum species from strawberry. Phytopathology 93:219-228.

Ninety-five isolates of Colletotrichum including 81 isolates of $C$. acutatum (62 from strawberry) and 14 isolates of C. gloeosporioides (13 from strawberry) were characterized by various molecular methods and pathogenicity tests. Results based on random amplified polymorphic DNA (RAPD) polymorphism and internal transcribed spacer (ITS) 2 sequence data provided clear genetic evidence of two subgroups in $C$. acutatum. The first subgroup, characterized as CA-clonal, included only isolates from strawberry and exhibited identical RAPD patterns and

acutatum population isolated from strawberry, the CA-clonal group is prevalent in Europe (54 isolates of 62). A subset of European C. acutatum isolates isolated from strawberry and representing the CA-clonal and CA-variable groups was assigned to two pathogenicity groups. No correlation could be drawn between genetic and pathogenicity groups. On the basis of molecular data, it is proposed that the CA-clonal subgroup contains closely related, highly virulent $C$. acutatum isolates that may have developed host specialization to strawberry. C. gloeosporioides isolates from Europe, which were rarely observed were either slightly or nonpathogenic on strawberry. The absence of correlation between genetic polymorphism and geographical origin in Colletotrichum spp. suggests a worldwide dissemination of isolates, probably through international plant exchanges.
\end{abstract} nearly identical ITS2 sequence analysis. A larger genetic group, CAvariable, included isolates from various hosts and exhibited variable RAPD patterns and divergent ITS2 sequence analysis. Within the $C$.
Additional keywords: Glomerella cingulata, internal transcribed spacer, phylogeny, rDNA.
Three species have been reported as causal agents of strawberry anthracnose, Colletotrichum acutatum J.H. Simmonds, C. fragariae Brooks, and C. gloeosporioides (Penz.) Penz. \& Sacc. (teleomorph Glomerella cingulata (Stoneman) Spauld. \& H. Schrenk) $(19,24)$. These species cause similar symptoms on strawberry including crown rot, fruit rot, and stolon lesions (15). In Europe, $C$. acutatum is the most prevalent species causing anthracnose, whereas $C$. gloeosporioides is found only occasionally, and $C$. fragariae has not yet been observed (5).

Colletotrichum spp. are currently identified using morphotaxonomic criteria such as morphological characters, i.e., conidial shape and size, appressorium morphology and size, setae morphology and temperature response on potato dextrose agar (PDA) medium $(12,18,24,29)$. Recently, a variety of molecular approaches have been used to discriminate various Colletotrichum spp. $(2,13,14)$ or to study the genetic diversity within Colletotrichum spp. $(9,27)$. Some of these studies have focused on Colletotrichum spp. isolated from strawberry, distinguishing the three species pathogenic on strawberry $(1,3,8,20,26)$.

Although important progress for identification of Colletotrichum spp. pathogenic on strawberry has been made, genetic diversity within these Colletotrichum spp. has been investigated to a lesser

Corresponding author: B. Denoyes-Rothan; E-mail address: denoyes@bordeaux.inra.fr

Publication no. P-2002-1213-03R

This article is in the public domain and not copyrightable. It may be freely reprinted with customary crediting of the source. The American Phytopathological Society, 2003. extent. Moreover, no correlation between genetic polymorphism and the two groups of pathogenicity (5) has been studied. The purpose of this work was (i) to investigate genetic polymorphism and pathogenicity of $C$. acutatum, the major pathogen isolated from strawberry in Europe, and (ii) to determine the genetic relatedness of this pathogen to representative isolates of $C$. acutatum obtained from strawberry and other hosts from various countries worldwide. In addition, isolates of $C$. gloeosporioides, observed occasionally on strawberry in Europe, were included in this work.

\section{MATERIALS AND METHODS}

Fungal isolates. The 62 isolates of $C$. acutatum isolated from strawberry were chosen from various collections representing a range of isolation dates (1978 to 1998) and geographic regions worldwide (Table 1). Nineteen $C$. acutatum isolates from other host plants were included in the study for comparison. Among these 81 isolates, 22 exhibiting a pink chromogenic coloring in culture are referred as $C$. acutatum chromogenic (Table 1). In addition, 13 isolates of $C$. gloeosporioides from strawberry originating from Europe and the United States and one isolate from mango used as an outgroup were studied. All isolates were singleconidia cultures. Stock cultures were maintained on silica gel at $4^{\circ} \mathrm{C}$ as described by Perkins (22). Cultures were initiated by transferring silica gel particles from the stock cultures to PDA (Difco Laboratories, Detroit, MI) plates to produce fungal material for molecular analysis and pathogenicity tests. All isolates were identified using classical taxonomic criteria such as conidial shape and growth on PDA (5). 
Isolation of genomic DNA. Fungal mycelium was produced in $200 \mathrm{ml}$ of liquid medium ( $24 \mathrm{~g} /$ liter of potato dextrose broth [PDB, Difco Laboratories], $1 \mathrm{~g} /$ liter of yeast extract [Difco Laboratories], and $1 \mathrm{~g} /$ liter of casein hydrolysate [Difco Laboratories]). Cultures were shaken at $100 \mathrm{rpm}$ for 5 days at $27^{\circ} \mathrm{C}$. Mycelium was harvested by filtration through mesh sieves $(40 \mu \mathrm{m})$, washed with sterile water, and deposited onto Whatman paper to remove excess water. Mycelium was ground to a fine powder in liquid nitrogen using a mortar and pestle and stored at $-80^{\circ} \mathrm{C}$. Three grams of mycelium powder was transferred to a $50-\mathrm{ml}$ tube, and DNA was extracted using a method adapted from Saghai-Maroof (23) by the addition of two chloroform/octanol phases and the addition of $10 \mathrm{mg} / \mathrm{ml}$ RNase A (Sigma Chemicals, St Quentin Fallavier, France). DNA concentration was assessed using spectrometric measurement (GeneQuant II, Pharmacia Biotech, Cambridge, UK).

PCR amplification. All 95 Colletotrichum isolates were analyzed using random amplified polymorphic DNA polymerase chain reaction (RAPD-PCR) (30,31). Amplifications were carried out in $15-\mu \mathrm{l}$ reaction mixtures containing $30 \mathrm{ng}$ of genomic DNA, $1.5 \mathrm{mM} \mathrm{MgCl}_{2}, 50 \mathrm{mM} \mathrm{KCl}, 10 \mathrm{mM}$ Tris-HCl (pH 8.6), $200 \mu \mathrm{M}$ each of dATP, dTTP, dCTP, and dGTP, $0.2 \mu \mathrm{M}$ ten-base primers (Operon Technologies, Rungis, France), $0.2 \mathrm{mg} / \mathrm{ml}$ bovine serum albumin, $0.05 \%$ (wt/vol) polyoxyethylene-ether W1 (Sigma Chemicals, St Quentin Fallavier, France), and 0.7 units of Taq DNA polymerase (Gibco BRL, Life Technologies, Cergy Pontoise, France). A Perkin-Elmer Cetus DNA thermal cycler (Model 9600, Perkin-Elmer Cetus Instruments Division, Courtaboeuf, France) was used with the following program: 1 min denaturation at $95^{\circ} \mathrm{C}$, 45 cycles of $10 \mathrm{~s}$ at $95^{\circ} \mathrm{C}, 15 \mathrm{~s}$ at $37^{\circ} \mathrm{C}$, and $2 \mathrm{~min}$ at $72^{\circ} \mathrm{C}$ and a final extension step of $5 \mathrm{~min}$ at $72^{\circ} \mathrm{C}$. Twenty RAPD primers were tested on six isolates (three strawberry isolates per species of Colletotrichum). Four primers (OPA13 [CAGCACCCAC], OPB07 [GGTGACGCAG], OPO02 [ACGTAGCGTC], and OPQ16 [AGTGCAGCCA]) that revealed clear and polymorphic patterns were selected for further RAPD analysis. All RAPD-PCR were performed twice. Universal PCR primers (ITS1, TCCGTAGGTGAACCTGCGG and ITS4, TCCTCCGCTTATT-

TABLE 1. Origin of the 95 analyzed single spore isolates of Colletotrichum spp. used in this study

\begin{tabular}{|c|c|c|c|c|c|}
\hline Isolates & Geographic origin & Host plant species & Date of isolation & Color on potato dextrose agar (PDA) $)^{\mathrm{a}}$ & RAPD ${ }^{b}$ genetic group \\
\hline \multicolumn{6}{|c|}{ C. acutatum from strawberry } \\
\hline $1079 \mathrm{a}$ & France & Strawberry & 1989 & Orange & CA-clonal \\
\hline $1267 b$ & France & Strawberry & 1988 & Orange & CA-clonal \\
\hline $1341 \mathrm{a}$ & France & Strawberry & 1990 & Orange & CA-clonal \\
\hline $162 \mathrm{a}$ & France & Strawberry & 1990 & Orange & CA-clonal \\
\hline $1641 \mathrm{a}$ & France & Strawberry & 1995 & Orange & CA-clonal \\
\hline $2033 a$ & France & Strawberry & 1995 & Orange & CA-clonal \\
\hline $2050 \mathrm{a}$ & France & Strawberry & 1992 & Orange & CA-clonal \\
\hline $2077 \mathrm{a}$ & France & Strawberry & 1995 & Orange & CA-clonal \\
\hline $2081 \mathrm{a}$ & France & Strawberry & 1995 & Orange & CA-clonal \\
\hline $2102 c$ & France & Strawberry & 1996 & Orange & CA-clonal \\
\hline $2184 a$ & France & Strawberry & 1992 & Orange & CA-clonal \\
\hline $2218 \mathrm{a}$ & France & Strawberry & 1992 & Orange & CA-clonal \\
\hline $318 \mathrm{a}$ & France & Strawberry & 1995 & Orange & CA-clonal \\
\hline $528 \mathrm{a}$ & France & Strawberry & 1990 & Orange & CA-clonal \\
\hline $66 b$ & France & Strawberry & 1992 & Orange & CA-clonal \\
\hline $688 b$ & France & Strawberry & 1990 & Orange & CA-clonal \\
\hline $703 a$ & France & Strawberry & 1996 & Orange & CA-clonal \\
\hline Cha-s & France & Strawberry & 1994 & Orange & CA-clonal \\
\hline Delorgueil.a & France & Strawberry & 1992 & Orange & CA-clonal \\
\hline F1a & France & Strawberry & 1985 & Orange & CA-clonal \\
\hline $\mathrm{F} 2 \mathrm{~b}$ & France & Strawberry & 1985 & Orange & CA-clonal \\
\hline $\mathrm{F} 2 \mathrm{c}$ & France & Strawberry & 1985 & Orange & CA-clonal \\
\hline F5a & France & Strawberry & 1985 & Orange & CA-clonal \\
\hline $\mathrm{F} 7 \mathrm{a}$ & France & Strawberry & 1984 & Orange & CA-clonal \\
\hline V1a & France & Strawberry & 1995 & Orange & CA-clonal \\
\hline $494 a$ & France & Strawberry & 1990 & Chromogenic & CA-variable \\
\hline $\mathrm{F} 3 \mathrm{c}$ & France & Strawberry & 1984 & Orange & CA-variable \\
\hline $\mathrm{F} 3 \mathrm{e}$ & France & Strawberry & 1984 & Orange & CA-variable \\
\hline All.F2a & Germany & Strawberry & 1995 & Orange & CA-clonal \\
\hline 87.8 .41 & Italy & Strawberry & 1994 & Orange & CA-clonal \\
\hline Cuneo.a & Italy & Strawberry & 1994 & Orange & CA-clonal \\
\hline Dana & Italy & Strawberry & 1994 & Orange & CA-clonal \\
\hline $2020 \mathrm{a}$ & Poland & Strawberry & 1995 & Orange & CA-clonal \\
\hline $1159.5 \mathrm{c}$ & Spain & Strawberry & 1988 & Orange & CA-clonal \\
\hline $1159.2 \mathrm{a}$ & Spain & Strawberry & 1988 & Orange & CA-variable \\
\hline Coll.11a & Switzerland & Strawberry & 1996 & Orange & CA-clonal \\
\hline Suisse.a & Switzerland & Strawberry & 1993 & Orange & CA-clonal \\
\hline Coll.15a & Switzerland & Strawberry & 1996 & Chromogenic & CA-variable \\
\hline $382 \mathrm{a}$ & United States & Strawberry & $\ldots$ & Orange & CA-clonal \\
\hline $388 \mathrm{a}$ & United States & Strawberry & $\ldots$ & Orange & CA-clonal \\
\hline $394 a$ & United States & Strawberry & $\ldots$ & Orange & CA-clonal \\
\hline Ca1B & United States & Strawberry & 1984 & Orange & CA-clonal \\
\hline CalA.a & United States & Strawberry & 1984 & Orange & CA-clonal \\
\hline CA-OH1 & United States & Strawberry & $\ldots$ & Orange & CA-clonal \\
\hline CT6 & United States & Strawberry & 1991 & Orange & CA-clonal \\
\hline Fla411 & United States & Strawberry & 1992 & Orange & CA-clonal \\
\hline
\end{tabular}

a Orange or chromogenic $=$ isolates exhibiting orange or pink chromogenic coloring on PDA culture, respectively.

b RAPD = random amplified polymorphic DNA.

${ }^{c}$ Other strawberry representatives included 138 clonal isolates from Israel (8). 
GATATGC) were used for amplification of the ITS1 and ITS2 regions between the small and large nuclear rDNA including the 5.8S rDNA from representative isolates of $C$. acutatum and $C$. gloeosporioides, which were selected according to RAPD analysis (one isolate per subgroup) (Table 2). For rDNA amplification, denaturation for $5 \mathrm{~min}$ at $95^{\circ} \mathrm{C}$ was followed by 40 cycles consisting of $30 \mathrm{~s}$ at $95^{\circ} \mathrm{C}, 30 \mathrm{~s}$ at $50^{\circ} \mathrm{C}$, and $1.5 \mathrm{~min}$ at $72^{\circ} \mathrm{C}$. The amplification products were analyzed by electrophoresis on $1.5 \%$ agarose gels stained with ethidium bromide and viewed under UV light. All ITS-PCR experiments were repeated at least four times with consistent results being achieved.

ITS2 sequencing procedure. PCR amplified rDNA products using the primer pair ITS1 and ITS4 (32) resulted in a product of approximately $560 \mathrm{bp}$, which was extracted from agarose gels using the Jetsorb kit (Genomed GmbH, Germany). The Big Dye Terminator DNA sequencing kit (Perkin-Elmer Inc., Branchburg, NJ) was used for determining the sequence of the ITS2 regions (32). The sequence was determined using an $\mathrm{ABI}$ prism 377 DNA sequencer (Applied Biosystem Inc., Foster
City, CA) and was performed at the Molecular Biology Center, Rehovot, Israel.

Pathogenicity tests. Pathogenicity of a subset of 38 European isolates of $C$. acutatum and C. gloeosporioides selected according to RAPD analysis, plus the isolate Goff from the United States, was assessed. To assign $C$. acutatum isolates to pathogenicity groups 1 or 2, two strawberry cultivars (Belrubi and Elsanta), were chosen as differential hosts (4). Cv. Belrubi is resistant to pathogenicity group 2 isolates and sensitive to pathogenicity group 1 isolates. Cv. Elsanta is susceptible to isolates in both pathogenicity groups and exhibits different severity of symptoms depending on the aggressiveness of isolates. Three 6-week-old plants originating from micropropagation were inoculated with each isolate by spraying a conidial suspension adjusted to $2 \times$ $10^{6}$ conidia per $\mathrm{ml}$, as previously described in a controlled environment chamber $\left(27 \pm 2^{\circ} \mathrm{C}, 90\right.$ to $95 \%$ relative humidity, and 14-h light) (5). Disease response was recorded 4 weeks after inoculation and based on a 0 to 5 disease severity scale where $0=$ no symptom and $5=$ dead plant (5).

TABLE 1. (continued from preceding page)

\begin{tabular}{|c|c|c|c|c|c|}
\hline Isolates & Geographic origin & Host plant species & Date of isolation & Color on potato dextrose agar (PDA) ${ }^{\mathrm{a}}$ & $\mathrm{RAPD}^{\mathrm{b}}$ genetic group \\
\hline Goff & United States & Strawberry & 1988 & Orange & CA-clonal \\
\hline J.Jenkins & United States & Strawberry & 1989 & Orange & CA-clonal \\
\hline L.Levigne & United States & Strawberry & 1989 & Orange & CA-clonal \\
\hline $\mathrm{La} 30$ & United States & Strawberry & 1998 & Orange & CA-clonal \\
\hline LLB10 & United States & Strawberry & 1988 & Orange & CA-clonal \\
\hline LLB5 & United States & Strawberry & 1986 & Orange & CA-clonal \\
\hline MD16 & United States & Strawberry & 1998 & Orange & CA-clonal \\
\hline Milla & United States & Strawberry & 1983 & Orange & CA-clonal \\
\hline Mil-2 & United States & Strawberry & 1984 & Orange & CA-clonal \\
\hline MS1 & United States & Strawberry & 1998 & Orange & CA-clonal \\
\hline $\mathrm{NC} 2$ & United States & Strawberry & 1998 & Orange & CA-clonal \\
\hline OKU1 & United States & Strawberry & 1992 & Orange & CA-clonal \\
\hline Cooley1b & United States & Strawberry & 1990 & Chromogenic & CA-variable \\
\hline Cooley2 & United States & Strawberry & 1990 & Chromogenic & CA-variable \\
\hline NY3 & United States & Strawberry & 1998 & Chromogenic & CA-variable \\
\hline TUT-5954 & Israel & Strawberry & 1996 & Orange & CA-clonal \\
\hline \multicolumn{6}{|c|}{ C. acutatum from various hosts } \\
\hline G4a & France & Lupin & 1984 & Orange & $\ldots$ \\
\hline Myrtille.a & France & Bilberry & 1995 & Chromogenic & CA-variable \\
\hline Patriot & France & Raspberry & 1995 & Chromogenic & CA-variable \\
\hline Coll.14a & Switzerland & Blackberry & $\ldots$ & Orange & $\ldots$ \\
\hline Coll.4a & Switzerland & Bilberry & 1996 & Chromogenic & CA-variable \\
\hline Coll36 & Switzerland & Blackberry & $\ldots$ & Chromogenic & CA-variable \\
\hline $120 \mathrm{~V} .2 \mathrm{II}$ & United States & Raspberry & 1993 & Chromogenic & $\ldots$ \\
\hline BB Pop\#11 & United States & Blueberry & 1994 & Chromogenic & CA-variable \\
\hline BB Pop\#19 & United States & Blueberry & 1994 & Chromogenic & CA-variable \\
\hline BJS Tomato & United States & Tomato & 1997 & Chromogenic & CA-variable \\
\hline CA-MIL & United States & Blackberry & 1987 & Chromogenic & CA-variable \\
\hline Clemson SF-21 & United States & Peach & 1993 & Chromogenic & CA-variable \\
\hline DA3 & United States & Dogwood & 1988 & Chromogenic & CA-variable \\
\hline Dolly BB\#25 & United States & Blueberry & 1995 & Chromogenic & CA-variable \\
\hline Nantana A1 & United States & Grape & 1995 & Chromogenic & CA-variable \\
\hline NC87-22 & United States & Apple & 1988 & Chromogenic & CA-variable \\
\hline RB-Ant-91E & United States & Raspberry & 1993 & Chromogenic & CA-variable \\
\hline Tomato ARK & United States & Tomato & 1988 & Chromogenic & CA-variable \\
\hline Wanda's tomato & United States & Tomato & 1996 & Chromogenic & CA-variable \\
\hline \multicolumn{6}{|l|}{ C. gloeosporioides } \\
\hline $9.89 \mathrm{r} 2$ & France & Strawberry & 1989 & & \\
\hline $9.89 \mathrm{n} 1$ & France & Strawberry & 1989 & & \\
\hline ArkP1 & United States & Strawberry & 1982 & & \\
\hline CG55a & United States & Strawberry & $\ldots$ & & \\
\hline CG63a & United States & Strawberry & $\ldots$ & & \\
\hline CG162a & United States & Strawberry & $\ldots$ & & \\
\hline 86.16 & United States & Strawberry & $\ldots$ & & \\
\hline 89.15 & United States & Strawberry & $\ldots$ & & \\
\hline $1159.5 \mathrm{~d}$ & Spain & Strawberry & 1988 & & \\
\hline $1159.5 \mathrm{e}$ & Spain & Strawberry & 1988 & & \\
\hline $\mathrm{Na} 1 \mathrm{a}$ & Japan & Strawberry & 1978 & & \\
\hline Shila & Japan & Strawberry & 1992 & & \\
\hline $\mathrm{Na} 8 \mathrm{a}$ & Japan & Strawberry & 1993 & & \\
\hline Manguier.a & Reunion & Mango & 1981 & & \\
\hline
\end{tabular}


Analysis of RAPD data. Only RAPD fragments clearly visible and observed in both experiments were considered for analysis. Presence or absence of fragments was scored as 1 or 0 , respectively. Genetic similarities between all pairs of isolates were computed using the formula given by Nei and Li (21): $S=2 b_{i} /\left(b_{i}+\right.$ $b_{j}$ ), where $b_{i j}$ is the number of fragments shared by two isolates, $i$ and $j$, and $b_{i}$ and $b_{j}$ are the total number of fragments found in isolates $i$ and $j$, respectively. Dissimilarities were computed as genetic distance $=1-\mathrm{S}$, and the data were used to construct a dendogram using the unweighted pair-group method with arithmetic average (UPGMA) (25). Distance calculations and construction of the dendogram were performed using Splus 3.1 software (Statistical Sciences Inc., Seattle, WA). Bootstrap analysis (6) was used to support the major groups observed in the dendogram. One hundred genetic dissimilarity matrixes were computed using the Splus software by generating 100 binary matrixes of the same size as the original RAPD data sets by random sampling with replacement. Data were analyzed with the programs Neighbor and Consense of the PHYLIP software package (Phylogeny Inference Package, J. Felsenstein, University of Washington) and used to construct the consensus UPGMA dendogram. Mean genetic dissimilarities between genetic groups were calculated as the arithmetical mean of all pairs of isolate of the two groups. Since the summary table of RAPD data is very large (69 markers), it was not convenient to include this table in the manuscript. All relevant information is available upon request from the corresponding author.

Phylogenetic analysis of sequence data. Analyses of internal transcribed spacer (ITS) sequences were carried out using the program package ARB (28). Alignment of sequences was performed with the implemented ARB automated alignment tool, and alignments were refined manually. Phylogenetic analyses were perform- ed by applying ARB parsimony, distance matrix, and maximumlikelihood methods. Branching order was similar in all methods used. To determine the robustness of phylogenetic trees, analyses were performed on the original data set and a data set from which highly variable positions were removed by use of a $50 \%$ conservation filter for the members of Colletotrichum to reduce potential tree artifacts that may result from multiple base changes. All sequences used in this study were aligned according to 155 bases in the ITS2 region and used for phylogenetic analysis. Analysis was conducted on sequences from representative isolates of $C$. acutatum from strawberry (Cha-s, France; 1267b, France; F3c, France; F3e, France; Cooley2, United States; Coll.15a, Switzerland; and TUT5954, Israel), tomato (BJS Tomato and Tomato ARK, United States), blackberry (Coll.14a, France), raspberry (120V.211, United States), grape (Nantana A.1, United States), and bilberry (Myrtille.a, France), of C. gloeosporioides from strawberry (1159.5d, Spain), and a number of Colletotrichum sequences previously sequenced by the authors $(9,11)$ as well as a number retrieved from GenBank (Table 2). As previously shown (9), DNA sequence analysis of the ITS2 region was more informative and showed a greater interspecies divergence than the ITS1 region alone. Complete ITS1-2 sequences of the isolates were submitted to GenBank with accession numbers appearing in Table 2.

Analyses of pathogenicity experiments. Six plants of each of the cvs. Belrubi and Elsanta were inoculated with the tested isolates. For statistical analysis, the means of disease rating from two experiments were pooled for each cultivar and isolate. Isolates of C. acutatum were assigned to pathogenicity group 1 when disease ratings were similar on cvs. Belrubi and Elsanta, and to pathogenicity group 2 when $\mathrm{cv}$. Belrubi was found to be much more resistant (disease rating $<1$ ) than $\mathrm{cv}$. Elsanta (disease rating $\geq 1$ ), according to Student's $t$ test $(P=0.05)$.

TABLE 2. Internal transcribed spacer (ITS) 2 sequences of Colletotrichum isolates used in this study

\begin{tabular}{|c|c|c|c|}
\hline Species & Isolate & Host & EMBL accession \\
\hline C. graminicola & $\mathrm{DR} 1^{\mathrm{a}}$ & Poа аппиа & AF 059676 \\
\hline C. linicola & CBS $172.51^{\mathrm{b}}$ & $\ldots$ & AB 046609 \\
\hline C. dematium & IMI-080025 & $\ldots$ & AB 046608 \\
\hline C. gloeosporioides & $\mathrm{CG} 231^{\mathrm{d}}$ & Fragaria $\times$ ananassa & AF 272780 \\
\hline C. gloeosporioides & AVO-37-4B ${ }^{d}$ & Persea americana & AF 207792 \\
\hline C. gloeosporioides & APL $7^{d}$ & Malus domestica & AF 272779 \\
\hline C. acutatum & IMI $348494^{\mathrm{d}}$ & Fragaria $\times$ ananassa & AF 272785 \\
\hline C. acutatum & TUT $5954^{d}$ & Fragaria $\times$ ananassa & AF 207794 \\
\hline C. acutatum & PCN $5^{\mathrm{d}}$ & Carya illinoensis & AF 272786 \\
\hline C. acutatum & PCH $8^{d}$ & Prunus persica & AF 272788 \\
\hline C. acutatum & ANE-HV83C ${ }^{\mathrm{d}}$ & Anemone coronaria & AF 272782 \\
\hline C. acutatum & STR $3^{\mathrm{d}}$ & Fragaria $\times$ ananassa & AF 272784 \\
\hline C. acutatum & ALM-US-4 ${ }^{\mathrm{d}}$ & Prunus dulcis & AF 207793 \\
\hline C. acutatum & IMI $223120^{\mathrm{d}}$ & Anemone coronaria & AF 272783 \\
\hline C. acutatum & APL $2^{\mathrm{d}}$ & Malus domestica & AF 272787 \\
\hline C. acutatum & ANE-NL12A ${ }^{\mathrm{d}}$ & Anemone coronaria & AF 272781 \\
\hline C. acutatum & IMI $345026^{\mathrm{d}}$ & Fragaria $\times$ ananassa & AF 272789 \\
\hline Colletotrichum & ALM-KSH-10 d & Prunus dulcis & AF 207791 \\
\hline C. gloeosporioides & $1159.5 \mathrm{~d}^{\mathrm{e}}$ & Fragaria $\times$ ananassa & AF 489568 \\
\hline C. acutatum & Myrtille. $\mathrm{a}^{\mathrm{e}}$ & Vaccinium myrtillus & AF 489567 \\
\hline C. acutatum & Tomato ARK ${ }^{\mathrm{e}}$ & Lycopersicon esculentum & AF 489560 \\
\hline C. acutatum & $\mathrm{F} 3 \mathrm{c}^{\mathrm{e}}$ & Fragaria $\times$ ananassa & AF 489566 \\
\hline C. acutatum & $\mathrm{F} 3 \mathrm{e}^{\mathrm{e}}$ & Fragaria $\times$ ananassa & AF 489561 \\
\hline C. acutatum & Nantana $\mathrm{A} 1^{\mathrm{e}}$ & Vitis sp. & AF 489559 \\
\hline C. acutatum & $120 \mathrm{~V} .211^{\mathrm{e}}$ & Rubus sp. & AF 489556 \\
\hline C. acutatum & Coll. $15 \mathrm{a}^{\mathrm{e}}$ & Fragaria $\times$ ananassa & AF 489557 \\
\hline C. acutatum & Cooley $2^{\mathrm{e}}$ & Fragaria $\times$ ananassa & AF 489558 \\
\hline C. acutatum & Coll.14a $\mathrm{a}^{\mathrm{e}}$ & Rubus sp. & AF 489563 \\
\hline C. acutatum & BJS Tomato ${ }^{\mathrm{e}}$ & Lycopersicon esculentum & AF 489565 \\
\hline C. acutatum & $1267 b^{e}$ & Fragaria $\times$ ananassa & AF 489562 \\
\hline C. acutatum & Cha-s ${ }^{e}$ & Fragaria $\times$ ananassa & AF 489564 \\
\hline
\end{tabular}

${ }^{a}$ Isolate sequenced by E. A. Travanty, L. M. Buttonow, R. T. Kane, S. B. Martin, J. S. Gregos, and D. P. Maxwell (unpublished) (EMBL Accession No. AF 059676).

${ }^{\mathrm{b}}$ Isolate sequenced by Moriwaki and Tsukiboshi, (unpublished, host not described) (EMBL Accession No. AB 046609).

${ }^{\mathrm{c}}$ Isolate sequenced by Moriwaki and Tsukiboshi, (unpublished, host not described (EMBL Accession No. AB 046608).

d Isolates sequenced by Freeman et al. (10).

e Isolates sequenced by authors. 


\section{RESULTS}

RAPD polymorphism. Four RAPD primers were used to amplify DNA from 95 Colletotrichum isolates. Sixty-nine reproducible RAPD fragments were obtained. Each primer yielded an average of 17 RAPD fragments, ranging in size from 450 to 3,200 bp. Representative RAPD banding patterns obtained using primer OPC02 and OPA13 are shown in Figure 1. UPGMA cluster analysis using the 69 RAPD fragments yielded a dendogram (Fig. 2). The 95 isolates clustered into two distinct groups (Fig. 2), CA and CG, C. acutatum and C. gloeosporioides, respectively. The 81 isolates of $C$. acutatum displayed 49 fragments. None were monomorphic or group CA-specific, whereas one was specific to all $C$. acutatum isolates except for isolate $120 \mathrm{~V}$-II. Three isolates, $120 \mathrm{~V}$ II from raspberry, Coll.14a from blackberry, and G4a from lupin displayed the most divergent patterns within group CA and showed 10, 5, and 5 specific fragments for each isolate, respectively. Within the CA group, two subgroups were distinguished that encompassed the 78 remaining $C$. acutatum isolates, CAclonal (54 isolates) and CA-variable (24 isolates). The 54 CAclonal isolates collected from strawberry during the years 1983 to 1998 in North America and Europe and displaying a salmonorange coloring in culture on PDA, clustered into one clade, present in $100 \%$ of the bootstrap-generated trees. All these isolates displayed identical banding patterns with a total of 11 monomorphic fragments, six of which were subgroup CA-clonal-specific and five of which were present in the RAPD patterns of several isolates in subgroup CA-variable. The $24 \mathrm{CA}$-variable isolates clustered into a more diverse genetic group and were collected from 1984 to 1998 from various host plants in North America and Europe (Table 1). These isolates, except for isolates F3e, F3c, and 1159-2a, exhibited a pink-chromogenic coloring in PDA culture.
The RAPD patterns of the 24 isolates in subgroup CA-variable displayed 22 fragments, eight of which were monomorphic. Five monomorphic fragments were specific to subgroup CA-variable. The CA-variable isolates of $C$. acutatum could be separated into two subgroups present in $99 \%$ of generated trees according to bootstrap analysis. One of them included all the isolates from tomato (three isolates), bilberry (three isolates), and grape (one isolate) and displayed four specific fragments; the other one included isolates from strawberry, peach, blackberry, dogwood, raspberry, bilberry, and apple and displayed two specific fragments.

The 14 isolates of $C$. gloeosporioides displayed 23 RAPD fragments, four of which were monomorphic. Among the four monomorphic fragments, three were specific to this group and one was also present in the RAPD patterns of two C. acutatum isolates, 120V-II and Coll.14a. The isolate Manguier.a from mango displayed the most divergent pattern within group CG containing six specific fragments. Within group CG, the 13 isolates from strawberry clustered into a subgroup that was present in $99 \%$ of the dendograms generated by bootstrap (Fig. 2). In this subgroup, two Japanese isolates, Na8a and Shila, were the most divergent, and all four European isolates, 1159.5d, 1159.5e, 9.89n1, and 9.89r2, clustered into a distinct subgroup which was well supported by bootstrap analysis (75\% of generated trees).

Sequence and phylogenetic analysis. Sequence analyses were conducted on representative isolates of CA-clonal, CA-variable, and CG chosen according to RAPD analysis (Table 2). Representatives of CA-clonal from strawberry included the isolates TUT5954 from Israel and Cha-s and 1267b from France. Representatives of CA-variable included: strawberry isolates F3c and F3e from France, Coll.15a from Switzerland, and Cooley2 from the United States; tomato isolates BJS Tomato and Tomato ARK from the United States; blackberry isolate Coll.14a from France;

CA

\section{CG}

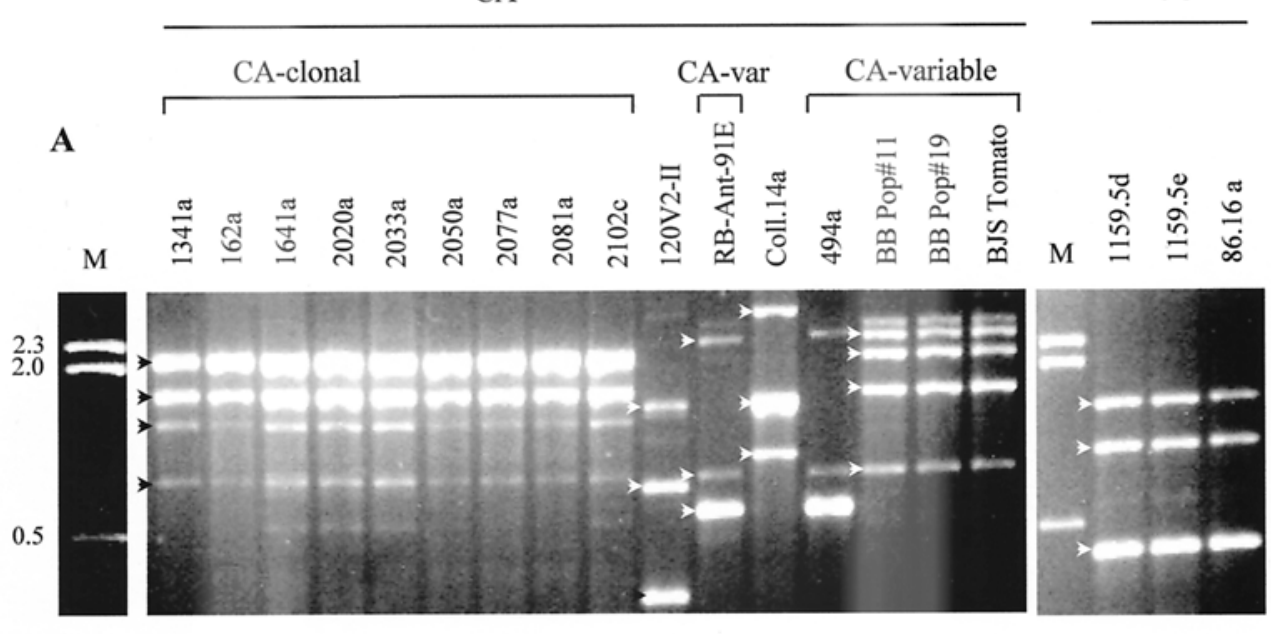

B

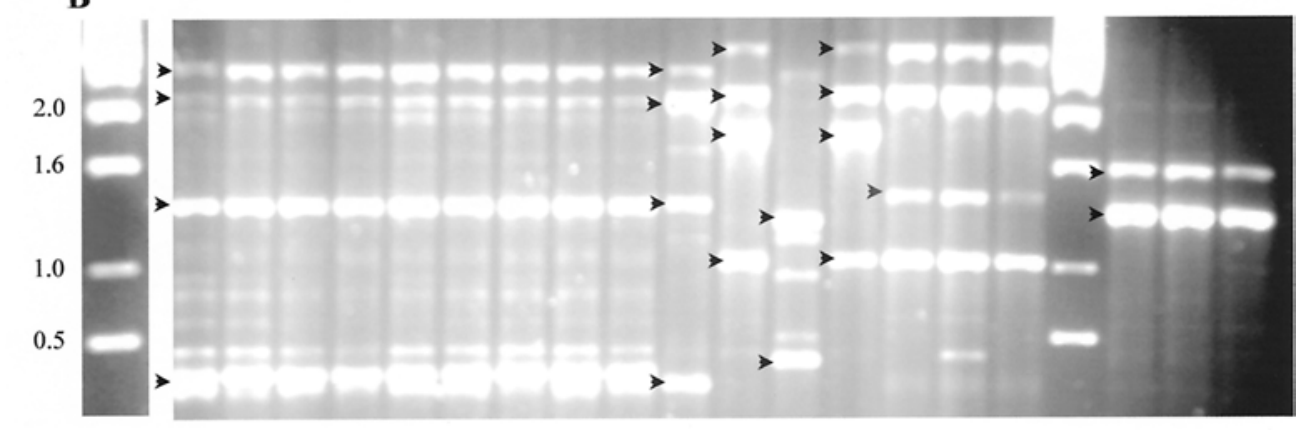

Fig. 1. Random amplified polymorphic DNA (RAPD) patterns of Colletotrichum acutatum (CA, 19 isolates) including subgroups CA-clonal (12 isolates) and CA-variable (five isolates), and isolates 120V2-II and Coll.14a, and RAPD patterns of $C$. gloeosporioides (CG, three isolates) obtained with A, primer OPC02 and $\mathbf{B}$, primer OPA13. Lane $\mathrm{M}=$ DNA markers in kilobases. 


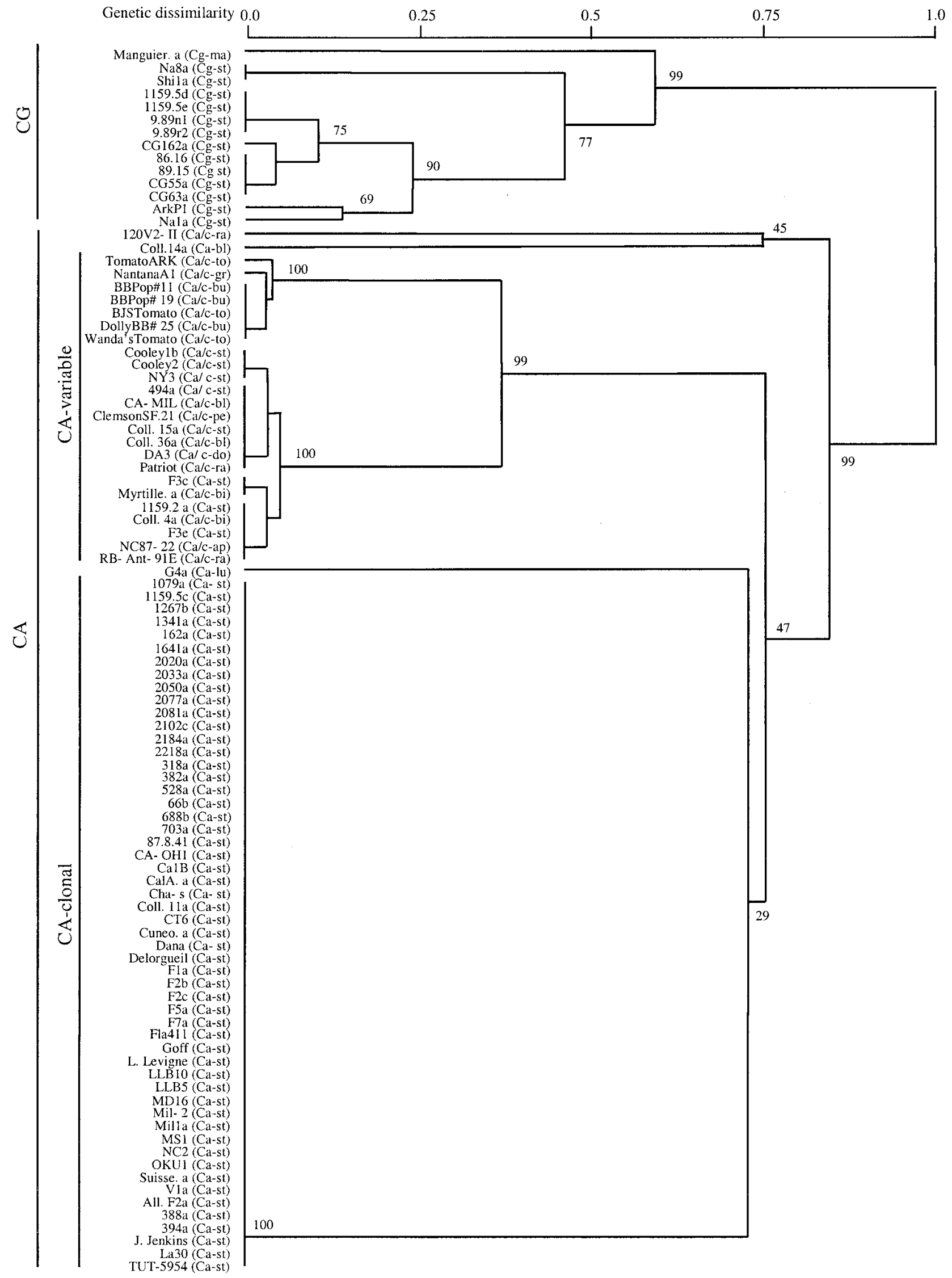

Fig. 2. Dendogram generated by unweighted pair-group method with arithmetic average cluster analysis of random amplified polymorphic DNA (RAPD) data from 95 isolates of two Colletotrichum species, C. acutatum and C. gloeosporioides. Numbers at major nodes indicate the number of times the group of isolates at the left of the node occurred among the sample of 100 bootstrap-generated dendograms. $\mathrm{CA}=C$. acutatum group; $\mathrm{CG}=C$. gloeosporioides group; Ca $=C$ acutatum $; \mathrm{Ca} / \mathrm{c}=C$. acutatum exhibiting pink chromogenic coloring in potato dextrose agar culture; and $\mathrm{Cg}=$ C. gloeosporioides. Host plants from the isolates are indicated: $\mathrm{ap}=$ apple; $\mathrm{bi}=$ bilberry; $\mathrm{bl}=$ blackberry; $\mathrm{bu}=$ blueberry; do = dogwood; $\mathrm{gr}=$ grape; $\mathrm{pe}=$ peach; ra = raspberry; st = strawberry; to = tomato; $\mathrm{lu}=$ lupin; and ma = mango. Scored bands are indicated by arrows. 
raspberry isolate 120V.2II from the United States; grape isolate Nantana A1 from the United States; and bilberry isolate Myrtille.a from France. The representative isolate $1159.5 \mathrm{~d}$ of $C$. gloeosporioides from strawberry from Spain was also sequenced.

Phylogenetic analysis was performed using the ITS2 region (Table 2; Fig. 3). Comparative analysis of ITS2 sequences produced a phylogenetic tree (Fig. 3) that supported the previous analysis published by Freeman et al. (9) and Sreenivasaprasad et al. (28). Analysis of sequences of the ITS2 fragments supported the phylogeny inferred from the RAPD dendogram grouping the $\mathrm{CG}$ isolates separately from the CA isolates. This analysis confirmed that 24 of the $C$. acutatum isolates, 12 from this study, were grouped separately from reference cultures of the species $C$. gloeosporioides, C. dematium, and $C$. graminicola. In addition, based on ITS2 sequence analysis two $C$. acutatum clusters were revealed, which corresponded to the CA-clonal and CA-variable subgroups previously identified by RAPD-PCR (Fig. 2). The three representative CA-clonal isolates were grouped together (nearly identical sequence), but apart from the other subgroup of CAvariable isolates. The CA-variable isolates were further grouped into subsets indicating the diversity of these populations (Fig. 3). The analysis was performed on ITS2 sequences of 12 isolates mentioned above, as well as 18 additional sequences of isolates available in GenBank (Table 2). It should be noted that sequences from submissions to GenBank were not independently confirmed in this study.

Pathogenicity testing. C. acutatum isolates were assigned to pathogenicity group 1 when disease ratings were similar on cvs. Belrubi and Elsanta, or to pathogenicity group 2 when cv. Belrubi was found to be resistant (disease rating of $<1$ ), while cv. Elsanta was susceptible (disease rating fo $\geq 1$ ) (Table 3). All the $35 C$. acutatum isolates inoculated onto strawberry caused at least one developing lesion on cv. Elsanta (disease rating of $\geq 1$ ), and were therefore considered as pathogenic on strawberry. Two isolates from group CA-clonal (i.e., isolates F7a and F2b) displayed a very low virulence level and were not assigned to any pathogenic group. The remaining $29 \mathrm{CA}$-clonal group isolates tested were assigned to pathogenicity group 1 (15 isolates) or 2 (14 isolates). Isolates collected during the years 1988 to 1994 displayed higher aggressiveness than those collected at the beginning of the 1980s (Table 3). All four inoculated CA-variable isolates, collected from 1984 to 1990, were assigned to pathogenicity group 1 . They displayed a relatively high level of aggressiveness. The four $C$. gloeosporioides isolates tested for pathogenicity produced only a few necrotic symptoms or none at all on both inoculated cultivars.

\section{DISCUSSION}

The main objective of this study was to investigate genetic diversity and pathogenicity of a large representative population of C. acutatum isolated from strawberry (62 isolates) mainly from Europe and the United States. Results based on RAPD and ITS2 sequence analyses provide clear genetic evidence of at least two well characterized groups among the tested isolates of $C$. acutatum from strawberry. Subgroup CA-clonal was homogeneous, containing isolates only from strawberry that exhibited identical RAPD patterns and nearly identical ITS2 sequence data. The other larger genetic subgroup, CA-variable, included isolates from various hosts including strawberry that exhibited variable RAPD patterns and ITS2 sequence. These two main subgroups were well supported by bootstrap analysis of RAPD markers and sequence phylogeny. According to RAPD analysis, isolates 120V.2II, Coll.14a, and G4a of C. acutatum could not be assigned to either of these two subgroups, CA-clonal and CA-variable. This suggests an extreme variation already known to exist in the broad species of $C$. acutatum $(9,18,29)$, and therefore additional subgroups such as that of isolate NL-12A from the ornamental anemone (11) may exist. However, all tested isolates of $C$. acutatum, including these three exceptions, were grouped within the $C$. acutatum species, which is confirmed by using ITS2 sequence analysis.

Past studies on C. acutatum were more focused on species identification, which is of paramount importance since $C$. acutatum is subjected to statutory quarantine requirements (16) than on genetic diversity. However, by using mtDNA, rDNA RFLPs, and isozymes the existence of one probable clonal population of $C$. acutatum on strawberry was suggested by Buddie et al. (3). Since these markers discriminate more efficiently between species than between subgroups within one species (17), we found it necessary to use RAPD markers to discriminate between subgroups within C. acutatum. This study confirms the existence of one CA-clonal group clearly distinct from other $C$. acutatum genetic subgroups such as CA-variable. In addition, the CA-clonal group, which included 54 of 62 strawberry isolates is the most prevalent group from this host in France, Israel, and probably in other European countries $(3,7)$. This subgroup also includes isolates from the United States. The larger genetic group, CA-variable, included eight additional $C$. acutatum strawberry isolates and $15 C$. acutatum isolates from other hosts producing orange to red or chromogenic pigment.

Freeman and Rodriguez (10) suggested two genetic distinct groups that were differentiated according to their ability to produce a red pigment (chromogenic). In this study, no clear correlation was found between genetic grouping and pigmentation since

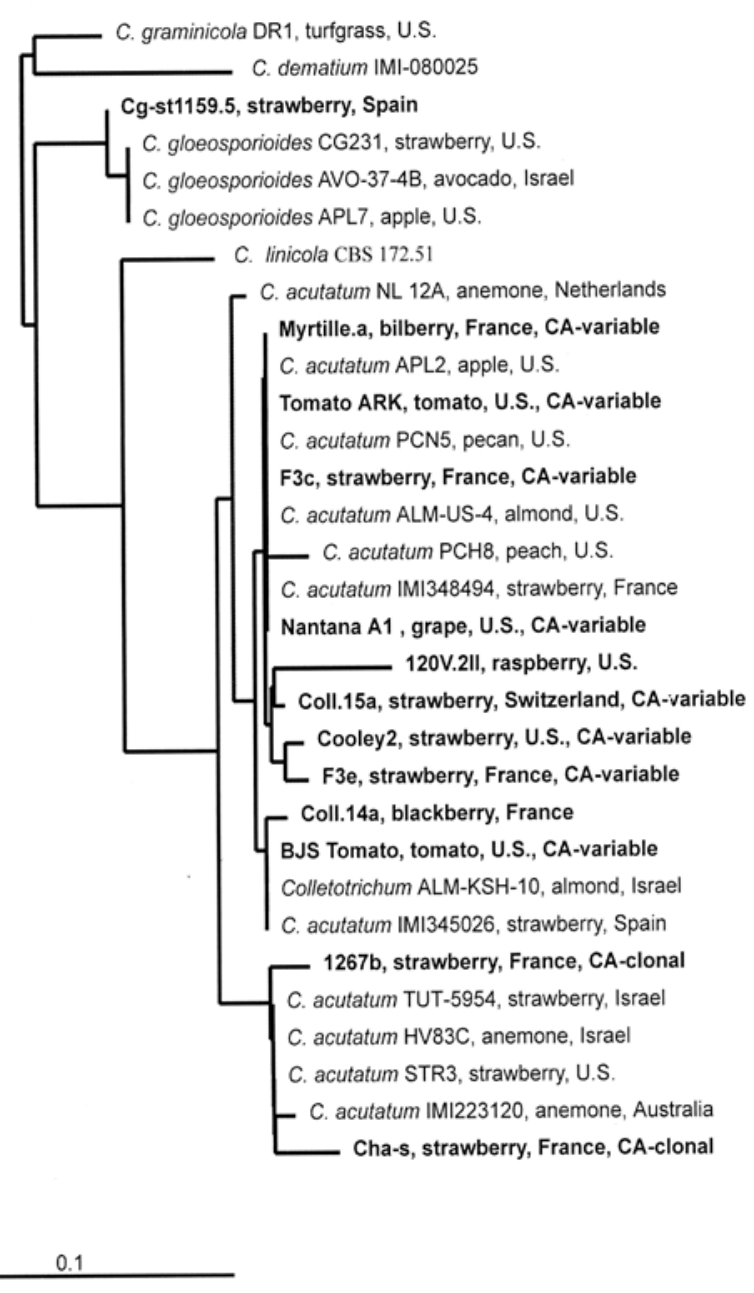

Fig. 3. Internal transcribed spacer 2-based phylogenetic tree of Colletotrichum isolates and published sequences. The tree was produced using the neighbor-joining algorithm. The orders of branching were similar in all tree construction approaches used (described in text). Scale bar indicates estimated $10 \%$ sequence divergence. 
20 of 23 C. acutatum isolates in subgroup CA-variable were chromogenic, whereas none of the 53 isolates within group CA-clonal possessed this trait. These results further support the existence of a polymorphic $C$. acutatum species, which include the chromogenic isolates $(9,12,27)$.

The low level of genetic polymorphism observed in subgroup CA-clonal containing only isolates from strawberry compared to subgroup CA-variable is consistent with a possible specialization of these isolates on strawberry, as suggested previously for $C$. acutatum isolates from almond (8) or for C. gloeosporioides isolates from mango $(13,14)$. Since $C$. acutatum is reported to be a polymorphic, polyphageous fungus (29), the low level of genetic polymorphism observed among isolates in group CA-clonal may thus be a consequence of a recent epidemic of clonal line(s) pathogenic on strawberry. The hypothesis of specialization of isolates on strawberry is strengthened by isolates in group CA-clonal being very aggressive, at least on some strawberry cultivars such as Elsanta, i.e., disease rating of 5 for the most aggressive isolates, compared with isolates in group CA-variable with a rating of 2.8 for the most aggressive isolates. However, CA-clonal isolates would have to be inoculated on other hosts to determine whether there are any differential levels of virulence compared to non CA- clonal isolates to confirm or reject the hypothesis of host specialization of CA-clonal isolates on strawberry.

Sreenivasaprasad et al. (26) suggested that European isolates of C. acutatum infecting strawberry were discrete from the United States $C$. acutatum isolates from a variety of hosts. In this study, no correlation was found between genetic grouping and geographical origin of $C$. acutatum isolates from strawberry (Table 1). This may be due to the large number of $C$. acutatum isolates from strawberry analyzed in our work. The lack of correlation between genetic grouping and geographical origin of $C$. acutatum isolates suggests that the pathogen may have been recently spread worldwide from a single or few sources of origin. Since large numbers of strawberry plants of the everbearing-types were imported at the beginning of the 1980s from the southwestern United States (5), introduction of $C$. acutatum into Europe may have occurred through contamination of traded plant material. This hypothesis is further supported by the occurrence of North American and European isolates from strawberry exhibiting identical RAPD patterns and ITS sequence data within both subgroups, CA-clonal and CA-variable. Furthermore, the C. acutatum species on strawberry is prevalent in Europe and various parts of the United States including California. Freeman and Katan (7) who

TABLE 3. Disease ratinga of European Colletotrichum strains isolated from strawberry

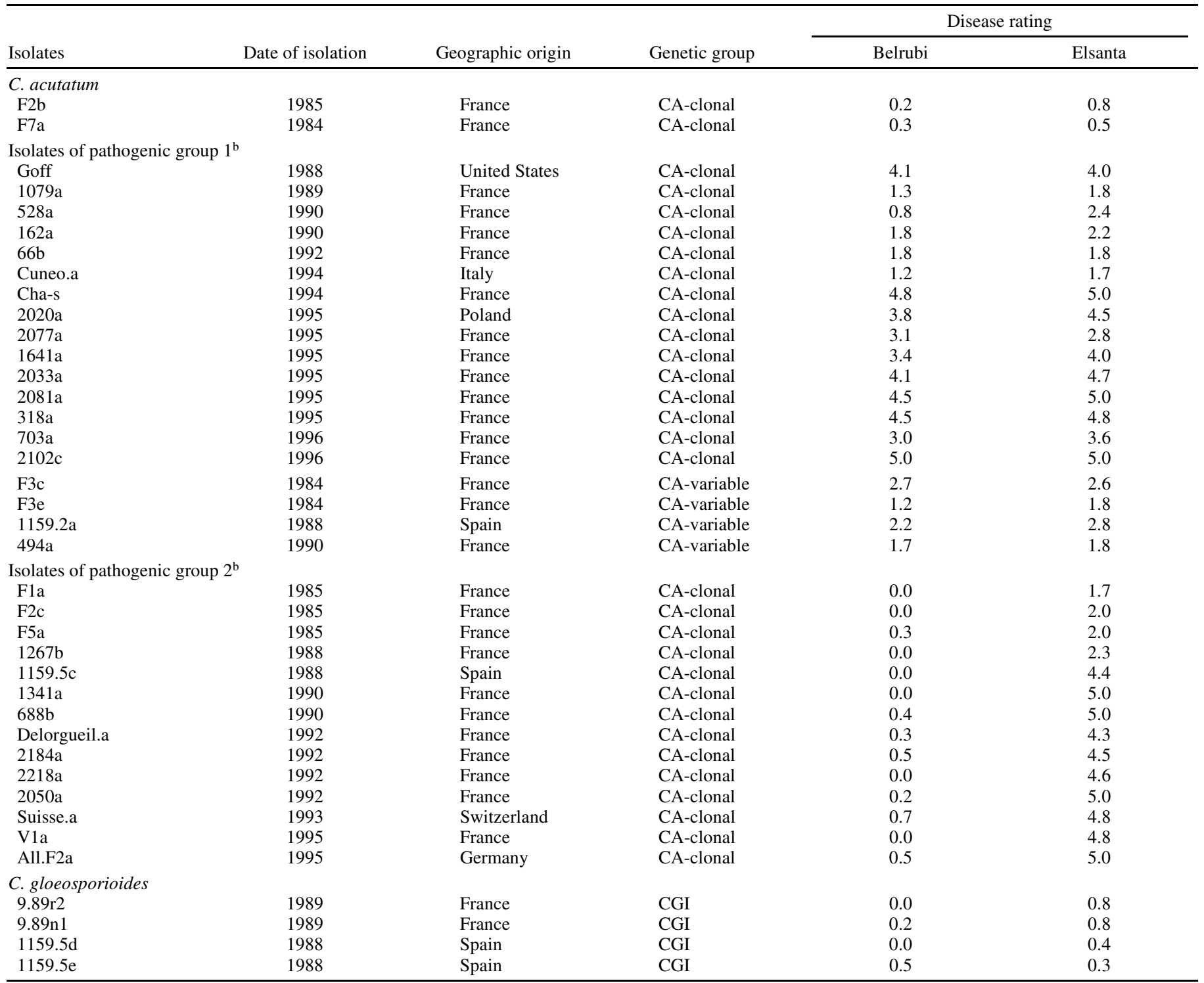

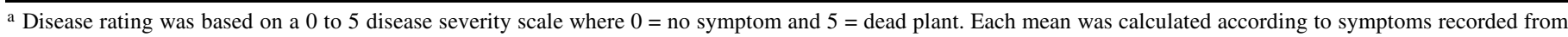
six plants of cvs. Belrubi and Elsanta from two experiments. Results were pooled.

${ }^{\text {b }}$ Isolates of $C$. acutatum were assigned to pathogenicity group 1 or group 2 according to their pathogenicity on cvs. Belrubi and Elsanta. 
observed identical RAPD patterns in isolates of the pathogen originating from both countries also suggested introduction of $C$. acutatum from the United States into Israel.

Using pathogenicity testing, 35 C. acutatum European isolates, collected from strawberry and representing the CA-clonal and CA-variable genetic subgroups were assigned to pathogenicity groups 1 and 2, as previously described (5). Assignment of $C$. acutatum isolates from strawberry to genetic subgroups and to pathogenicity groups was not correlated (Table 3 ). Within each group, isolates varied in aggressiveness (Table 3). Isolates collected after 1988 or 1994 displayed significantly higher levels of aggressiveness. The introduction of $C$. acutatum into Europe most likely occurred at the beginning of the 1980s (5). Therefore, variation in pathogenicity cannot be explained by host specialization of this group. The analysis of genetic polymorphism and variation in pathogenicity among CA-clonal isolates suggests that isolates within this subgroup are closely related genetically but not identical, which may be further studied with additional molecular markers such as amplified fragment length polymorphisms (AFLPs). A possible explanation for the pathogenic differentiation within CA-clonal is the adaptation and disease incidence of these isolates on resistant strawberry cultivars with major resistance genes such as the Californian cultivar, e.g., Chandler, and resistant European cultivar, e.g., Belrubi (7). This hypothesis is supported by the occurrence of highly virulent isolates assigned to pathogenicity group 1 which overcame the major dominant resistance gene of Chandler in 1994, in the Val de Loire (Central France) (4).

For the first time, four European isolates of $C$. gloeosporioides from strawberry that have been rarely observed were included in a study of genetic polymorphism and pathogenic variability. RAPD patterns of all 14 isolates of $C$. gloeosporioides showed high level of polymorphism as previously described (10). Because isolates of C. gloeosporioides from strawberry collected in Europe and the United States were closely related genetically, it is possible that $C$. gloeosporioides isolates pathogenic on strawberry were also introduced into Europe from North America through plant trade, as suggested for $C$. acutatum. Dissemination of $C$. gloeosporioides and $C$. acutatum through plant exchange between Europe and the United States, and genetic and pathogenic variation within both species, could be further investigated using Californian and European C. acutatum and C. gloeosporioides isolates.

Whereas high levels of virulence were reported elsewhere for isolates of $C$. gloeosporioides from the southeastern United States (15), European isolates of $C$. gloeosporioides collected from strawberry exhibited low virulence (Table 3 ) and could even be considered as nonpathogenic. This may be due to a difference between European and southeastern United States isolates or to the temperate climatic conditions occurring in Europe. The latter hypothesis is supported by the fact that optimal growth of C. gloeosporioides is obtained in vitro at higher temperatures than that for $C$. acutatum (24). Alternatively, low levels of virulence of $C$. gloeosporioides on strawberry observed in Europe could be related to limited epidemics of this species on strawberry in this region.

RAPD fragments specific to the different genetic groups of $C$. acutatum, CA-clonal and CA-variable, may be very useful for designing specific PCR-primers for rapid and reliable detection and for differentiation between the subgroups pathogenic on strawberry. This is of particular interest for detection of $C$. acutatum and identification of the genetic groups, CA-clonal or CA-variable, for epidemiological studies. Moreover, using additional primers or other markers such as AFLPs would increase the chance of detecting avirulence genes that are related to pathogenic variability. This could be used to discriminate between the two pathogenicity groups in group CA-clonal, and to differentiate between the highly virulent United States isolates of $C$. gloeosporioides compared to the predominantly mildly virulent isolates in Europe.

\section{ACKNOWLEDGMENTS}

We thank Alain Baudry, L. Black, E. Bosshard, C. Chandler, D. Cooley, M. Ellis, J. Gondran, M. Maltoni, M. Meyer, R. D. Milholland, J. G. Nourrisseau, and K. Okayama for providing isolates of Colletotrichum spp. This research was supported in part by a grant from the "Région Aquitaine" (PDZR) and European FEDER for strawberry research awarded to B. Denoyes-Rothan and by Research Grant Award IS 2825-97 from BARD, The United States-Israel Binational Agricultural Research and Development Fund awarded to S. Freeman.

\section{LITERATURE CITED}

1. Bonde, M. R., Peterson, G. L., and Maas, J. L. 1991. Isozyme comparisons for identification of Colletotrichum species pathogenic to strawberry. Phytopathology 81:1523-1528.

2. Brown, A. E., Sreenivasaprasad, S., and Timmer, L. W. 1996. Molecular characterization of slow-growing orange and key lime anthracnose strains of Colletotrichum from citrus as C. acutatum. Phytopathology 86:523-527.

3. Buddie, A. G., Martinez-Culebras, P., Bridge, P. D., Garcia, M. D., Querol, A., Cannon, P. F., and Monte, E. 1999. Molecular characterization of Colletotrichum strains derived from strawberry. Mycol. Res. 103:385-394.

4. Denoyes-Rothan, B. 1997. Etude des relations hôte-pathogène chez le couple Fraragaria $\times$ ananassa et Colletotrichum spp. Ph.D. thesis. Université de Bordeaux II, France.

5. Denoyes, B., and Baudry, A. 1995. Species identification and pathogenicity study of French Colletotrichum strains isolated from strawberry using morphological and cultural characteristics. Phytopathology 85:5357.

6. Felsenstein, J. 1985. Confidence limits on phylogenies: An approach using the bootstrap. Evolution 39:783-791.

7. Freeman, S., and Katan, T. 1997. Identification of Colletotrichum species responsible for anthracnose and root necrosis of strawberry in Israel. Phytopathology 87:516-521.

8. Freeman, S., Katan, T., and Shabi, E. 1998. Characterization of Colletotrichum species responsible for anthracnose diseases of various fruits. Plant Dis. 82:596-605.

9. Freeman, S., Minz, D., Maymon, M., and, Zveibil, A. 2001. Genetic diversity within Colletotrichum acutatum sensu Simmonds. Phytopathology 91:586-592.

10. Freeman, S., and Rodriguez, R. J. 1995. Differentiation of Colletotrichum species responsible for anthracnose of strawberry by arbitrarily primed PCR. Mycol. Res. 99:501-504.

11. Freeman, S., Shabi, E., and Katan, T. 2000. Characterization of Colletotrichum acutatum causing anthracnose disease of anemone. Appl. Environ. Microbiol. 66:5267-5272.

12. Gunnell, P. S., and Gubler, W. D. 1992. Taxonomy and morphology of Colletotrichum species pathogenic to strawberry. Mycologia 84:157-165.

13. Hayden, H. L., Pegg, K. G., Aitken, E. A. B., and Irwin, J. A. G. 1994. Genetic relationship as assessed by molecular markers and crossinfection among strains of Colletotrichum gloeosporioides. Aust. J. Bot. 42:9-18.

14. Hodson, A., Mills, P. R., and Brown, A. E. 1993. Ribosomal and mitochondrial DNA polymorphisms in Colletotrichum gloeosporioides isolated from tropical fruits. Mycol. Res. 97:329-335.

15. Howard, C. M., Maas, J. L., Chandler, C. K., and Albregts, E. E. 1992. Anthracnose of strawberry caused by the Colletotrichum complex in Florida. Plant Dis. 76:976-981.

16. Journal Officiel de la République Française. 1993. Arrété du 2 septembre 1993 relatif aux exigences sanitaires des végétaux, produits végétaux et autres objets. 4 novembre 1993. Ed. Ministère de 1'Agriculture et de la Pêche.

17. Kohn, L. M. 1992. Developing new characters for fungal systematics: An experimental approach for determining the rank of resolution. Mycologia 84:139-153.

18. Lenné, J. M. 1977. A study of the biology and taxonomy of the genus Colletotrichum. Ph.D. thesis. University of Melbourne, Australia.

19. Maas, J. L. 1987. Compendium of Strawberry Diseases. The American Phytopathological Society, St. Paul, MN.

20. Martinez-Culebras, V., Barrio, E., Garcia, M. D., and Querol, A. 2000. Identification of Colletotrichum species responsible for anthracnose of strawberry based on the internal transcribed spacers of the ribosomal region. FEMS Microbiol. Lett. 189:97-101.

21. Nei, M., and Li, W. 1979. Mathematical model for studying genetic variation in terms of restriction endonucleases. Proc. Natl. Acad. Sci. 76:5269-5273.

22. Perkins, D. D. 1962. Preservation of Neurospora stock cultures with 
anhydrous silica gel. Can. J. Microbiol. 8:591-594.

23. Saghai-Maroof, M. A., Soliman, K. M., Jorgensen, R. A., and Allard, R. W. 1984. Ribosomal DNA spacer-length polymorphism in barley: Mendelian inheritance, chromosomal location, and population dynamics. Proc. Natl. Acad. Sci. USA 81:8014:8018.

24. Smith, B. J., and Black, L. L. 1990. Morphological, cultural, and pathogenic variation among Colletotrichum species isolated from strawberry. Plant Dis. 74:69-76.

25. Sokal, R. R., and Michener, C. D. 1958. A statistical method for evaluating systematic relationships. Univ. Kans. Sci. Bull. 38:1409-1438.

26. Sreenivasaprasad, S., Brown, A. E., and Mills, P. R. 1992. DNA sequence variation and interrelationships among Colletotrichum species causing strawberry anthracnose. Physiol. Mol. Plant Pathol. 41:265-281.

27. Sreenivasaprasad, S., Mills, P. R., Meehan, B. M., and Brown, A. E. 1996. Phylogeny and systematics of 18 Colletotrichum species based on ribosomal DNA spacer sequences. Genome 39:499-512.
28. Strunk, O., Ludwig, W., Gross, O., Reichel, B., Stuckmann, N., May, M., Nonhoff, B., Lenke, M., Ginhart, T., Vilbig, A., and Westran, R. 1998. ARB-A software environment for sequence data. Technische Universität München, Munich, Germany.

29. Sutton, B. C. 1980. The Coelomycetes Fungi Imperfecti with Pycnidia, Acervuli and Stromata. CMI, Kew, Surrey, UK.

30. Welsh, J., and McClelland, M. 1990. Fingerprinting genomes using PCR with arbitrary primers. Nucleic Acids Res. 18:7213-7218.

31. Williams, J. G. K., Kubelick, A. R., Livak, K. J., Rafalski, J. A., and Tingey, S. V. 1990. DNA polymorphism amplified by arbitrary primers are useful as genetic markers. Nucleic Acids Res. 18:6531-6535.

32. White, T. J., Bruns, T., Lee, S., and Taylor, J. 1990. Amplification and direct sequencing of fungal ribosomal RNA genes for phylogenetics. Pages 315-322 in: PCR Protocols, A Guide to Methods and Applications. M. A. Innis, D. H. Gelfand, and J. J. Sninsky, eds. Academic Press, San Diego, CA. 